\title{
Validity and Reliability of a Korean Version of the Patulous Eustachian Tube Handicap Inventory (K-PHI) Questionnaire
}

\author{
Ji-A Kim, MD, Sung-Won Choi, $\mathrm{MD}, \mathrm{PhD}^{\dagger}$, Se-Joon $\mathrm{Oh}, \mathrm{MD}, \mathrm{PhD}^{\dagger}$ and Soo-Keun Kong, $\mathrm{PhD}$ \\ Department of Otorhinolaryngology and Biomedical Research Institute, Pusan National University Hospital, \\ Busan, Korea
}

\begin{abstract}
- ABSTRACT -
Background and Objectives: Patulous Eustachian tube (PET) is a rare disease, but it seriously affects patients' quality of life. There are various treatment methods for PET; however there are no standardized treatment guidelines. The PET handicap inventory (PHI) proposed by Ikeda in Japan has been an effective tool for evaluating the severity of PET. In this study, we evaluated the reliability and validity of the Korean version of PHI (K-PHI). Materials and Methods: Translation of the PHI into Korean was performed by two bilingual otologists. K-PHI was applied to the PET patients at the initial visit and after the treatment, and statistical analysis was performed to evaluate the reliability and validity of the K-PHI. Patients were divided into two groups according to their treatment methods, and their K-PHI scores were categorized and compared. Results: The Cronbach's alpha value of the K-PHI was 0.889 , similar to the original version PHI (0.887). The Spearman rank correlation coefficients among the ten items, total score, and visual analog scale score for the PET symptoms and total score were calculated, and the significant values were less than 0.05 . Conclusions: The K-PHI is a reliable and valid questionnaire to evaluate the severity of PET. Therefore, after an accurate diagnosis is made, the K-PHI can be applied to follow PET patients' symptoms. (J Clinical Otolaryngol 2021;32:111-117)
\end{abstract}

KEY WORDS: Eustachian tube, Surveys and questionnaires, Translation, Reproducibility of results.

\section{Introduction}

The Eustachian tube plays a critical role in middle ear function. When there is continued abnormal patency in the Eustachian tube, it can be defined as a patulous Eustachian tube (PET). ${ }^{1,2)}$ PET is a rare disease, but if symptoms like autophony or aural fullness are present, it reduces the patient's quality of life and, in extreme cases, may even cause depression. ${ }^{1)}$ There are various treatment methods for PET from conservative therapy to surgical management. For effective symptom control, it is important not only to accurately diagnose PET, but also appropriately evaluate the severity of PET. Ikeda et al. proposed a new scoring system for evaluating PET, as the PET handicap inventory (PHI). ${ }^{3)}$

As the proposed PHI questionnaire for PET is available in English, translation into Korean is necessary for patients in our hospital in Pusan, Korea. As the translation process may alter the intent or meaning of the questionnaire items, validation of the translated questionnaire is essential. The PHI consists of ten items on a self-scoring questionnaire, and it shows high reliability. $^{3)}$

Therefore, this study aimed to evaluate the reliability

Received: June 20, 2021 / Revised: July 13, 2021 / Accepted: August 9, 2021

${ }^{\dagger}$ These authors contributed equally to this work.

Corresponding author: Soo-Keun Kong, Department of Otorhinolaryngology and Biomedical Research Institute, Pusan National University Hospital, Busan 49241, Korea

Tel: +82-51-240-7332 ·Fax: +82-51-246-8668·E-mail: entkong@gmail.com 
and validity of the Korean version of the PHI (K-PHI).

\section{Materials and Methods}

\section{Subjects}

This study was a retrospective chart review. A total of 234 patients visited our otorhinolaryngology clinic for various symptoms of PET, including voice or breathing autophony, aural fullness, or tinnitus. The following inclusion criteria for patients were applied during participant selection: 1) age $>18$ years, 2) diagnosis as definite PET or possible PET based on criteria, ${ }^{4)} 3$ ) conducting two questionnaires for PET symptoms using the visual analog scale (VAS) and K-PHI. This study was approved by our Institutional Review Board in Pusan National University Hospital, Korea (IRB No. 2102002-099).

Moreover, we excluded patients with the following conditions: 1) patients with other otologic diseases, such as chronic otitis media, cholesteatoma, or mastoiditis, requiring surgical treatment; 2) patients with a history of previous surgical treatment for Eustachian tube dysfunction, and 3) patients who refused or missed the two questionnaires.

According to these criteria, 106 patients were included in this study. We applied otoscopic examination, pure tone audiometry, pitch match and loudness match, VAS for PET symptoms, and the K-PHI questionnaire to these patients. After the diagnosis of PET was made, treatment methods were determined by comprehensively considering the duration of symptoms, severity, local findings, and patient preference.

\section{Translation of PHI into Korean}

We translated the main version of the PHI into Korean. The first translation process into Korean was independently conducted by two bilingual otologists. Then, back-translation into English was conducted for equivalence. Finally, a third otologist confirmed the final ver- sion of the questionnaire, which was named K-PHI.

\section{Measurement of questionnaire validity and reli- ability}

After diagnosis as PET and before treatment, all patients responded to the K-PHI and VAS for voice autophony, breathing autophony, and aural fullness.

To determine reliability, Cronbach's alpha coefficient was used. Cronbach's alpha measures to assess internal consistency in each item and total items. To evaluate whether the results of K-PHI were normally distributed or not, we performed the Kolmogorov-Smirnov test. The results were not normally distributed. Therefore, to determine the validity of the K-PHI questionnaire, the relationships between each item and total K-PHI were evaluated using the Spearman rank correlation coefficient. If there is significant correlation between each item and total score, it means the item is valid. To evaluate whether the questionnaire items sufficiently reflect the patients' symptoms, relationships between the K-PHI and other measurements (VAS for voice autophony, VAS for breathing autophony, VAS for aural fullness, age, duration of symptoms, and hearing threshold) were confirmed using the Spearman rank correlation coefficient. Moreover, we divided the patients into two groups according to their treatment methods and compared their severity and total score using the chi-square test. We used IBM SPSS ver. 19.0 (IBM, Armonk, NY, USA) for the statistical analysis.

\section{Results}

The basal characteristics of 106 patients were analyzed. Of these patients, 37 were male and 69 were female. The mean age of patients was $35.3 \pm 11.9$ years, the mean duration of symptoms was $46.3 \pm 53.0$ months, and 24 patients (23.9\%) had a sniffing habit (Table 1).

To determine the reliability of K-PHI, the internal consistency of the K-PHI was examined using Cron- 
Table 1. Basal characteristics of participants

\begin{tabular}{ll}
\hline \multicolumn{1}{c}{ Characteristic } & Mean \pm SD (range) \\
\hline Age (year) & $35.3 \pm 11.9$ (18-76) \\
Sex (male:female) & $37: 69$ \\
Duration of symptoms (month) & $45.3 \pm 53.0(0.5-240)$ \\
Site of symptoms & \\
Right & 34 \\
Left & 22 \\
Both & 50 \\
Hearing threshold (dB) & $10.58 \pm 8.77(0-53.33)$ \\
Sniffing habit exist & $24(22.6 \%)$ \\
Visual analogue scale (0-10) & \\
Voice autophony & $5.6 \pm 2.7$ \\
Breathing-sound autophony & $5.8 \pm 2.7$ \\
Aural fullness & $5.9 \pm 2.5$ \\
K-PHI score & $21.6 \pm 10.7$ \\
Treatment methods & \\
Conservative treatment & 67 \\
Surgical treatment & 39 \\
\hline
\end{tabular}

K-PHI: Korean version of PHI.

bach's alpha. The Cronbach's alpha value of the K-PHI was 0.889 , and Cronbach's alpha values for each item are presented in Table 2.

In determining the validity of the K-PHI, correlation between each items and total score were calculated using Spearman rank correlation coefficients in Table

Table 2. Reliability testing using Cronbach alpha coefficients for internal consistency

\begin{tabular}{ccc}
\hline $\begin{array}{c}\text { Item } \\
\text { No. }\end{array}$ & $\begin{array}{c}\text { Item-total } \\
\text { correlation }\end{array}$ & $\begin{array}{c}\text { Cronbach alpha } \\
\text { coefficient } \\
\text { without this item }\end{array}$ \\
\hline 1 & 0.603 & 0.880 \\
2 & 0.406 & 0.893 \\
3 & 0.650 & 0.877 \\
4 & 0.401 & 0.895 \\
5 & 0.711 & 0.872 \\
6 & 0.710 & 0.872 \\
7 & 0.769 & 0.868 \\
8 & 0.801 & 0.865 \\
9 & 0.676 & 0.875 \\
10 & 0.554 & 0.883 \\
\hline
\end{tabular}

3. Moreover, Spearman rank correlation coefficients between other measurements and total K-PHI scores are calculated (Table 4). There were significant correlations between the K-PHI and each VAS symptom score, but no significant relationship between age, symptom duration, or hearing threshold.

The patients were divided into two groups according to the treatment methods: conservative treatment group

Table 3. Validity testing using Spearman rank correlation coefficients among 10 items of K-PHI

\begin{tabular}{cl}
\hline Item No & Total \\
\hline 1 & $0.663^{*}$ \\
2 & $0.505^{*}$ \\
3 & $0.740^{*}$ \\
4 & $0.527^{*}$ \\
5 & $0.774^{*}$ \\
6 & $0.778^{*}$ \\
7 & $0.816^{*}$ \\
8 & $0.853^{*}$ \\
9 & $0.742^{*}$ \\
10 & $0.671^{*}$ \\
\hline Total & 1.000 \\
\hline
\end{tabular}

* Correlation is significant at the 0.01 level (2-tailed). $\mathrm{K}-\mathrm{PHI}$ : Korean version of PHI.

Table 4. Spearman rank correlation between total K-PHI score and other measurements

\begin{tabular}{lc}
\hline \multicolumn{1}{c}{ Variables } & $\begin{array}{c}\text { Spearman rank } \\
\text { correlation coefficient }\end{array}$ \\
\hline VAS for voice autophony & $0.285^{*}$ \\
$(p=0.003)$ \\
VAS for breathing-sound & $0.215 \dagger$ \\
autophony & $(p=0.027)$ \\
VAS for aural fullness & $0.209 \dagger$ \\
Age & $(p=0.032)$ \\
& 0.066 \\
Duration of symptoms & $(p=0.500)$ \\
Mean hearing threshold & 0.063 \\
& $(p=0.520)$ \\
& $(p=0.092$ \\
\end{tabular}

* Correlation is significant at the 0.01 level (2-tailed).

† Correlation is significant at the 0.05 level (2-tailed).

K-PHI: Korean version of PHI, VAS: visual analog scale. 
$(n=67)$ and surgical treatment group $(n=39)$. The total score of K-PHI averaged 21.6 \pm 10.7 in all patients, $20.1 \pm 10.7$ in the conservative treatment group, and $24.4 \pm 10.1$ in the surgical treatment group. There was a significant difference in the initial K-PHI score between the two groups $(\mathrm{p}<0.05)$.

The K-PHI was categorized as no handicap (0-8), mild handicap (10-16), mild handicap (18-24), and severe handicap (26-40) according to Ikeda's study. All participants completed the K-PHI questionnaire before treatment. In the conservative treatment group, there were $12(17.9 \%)$ patients with no handicap, 21 (31.3\%) had mild handicap, 11 (16.4\%) had moderate handicap, and $23(34.3 \%)$ had severe handicap. In the surgical treatment group, there were $5(12.8 \%)$ patients with no handicap, 3 (7.7\%) had mild handicap, 6 (15.4\%) had mild handicap, and 25 (64.1\%) had severe handicap (Fig. 1).

K-PHI was applied at first visit of 106 patients. Follow-up K-PHI was applied to the patients who agreed to repeated test. In conservative treatment group, 19 out of 67 patients did follow-up K-PHI after the conservative treatment at least more than 2 months. Mean score of K-PHI was $15.8 \pm 9.2$ before the conservative treatment and $8.7 \pm 6.9$ after the treatment. The average difference of K-PHI after the conservative treatment was 7.1 \pm 10.5 . In surgical treatment group, 33 out of 39 did follow-up K-PHI after the surgery. Mean score of

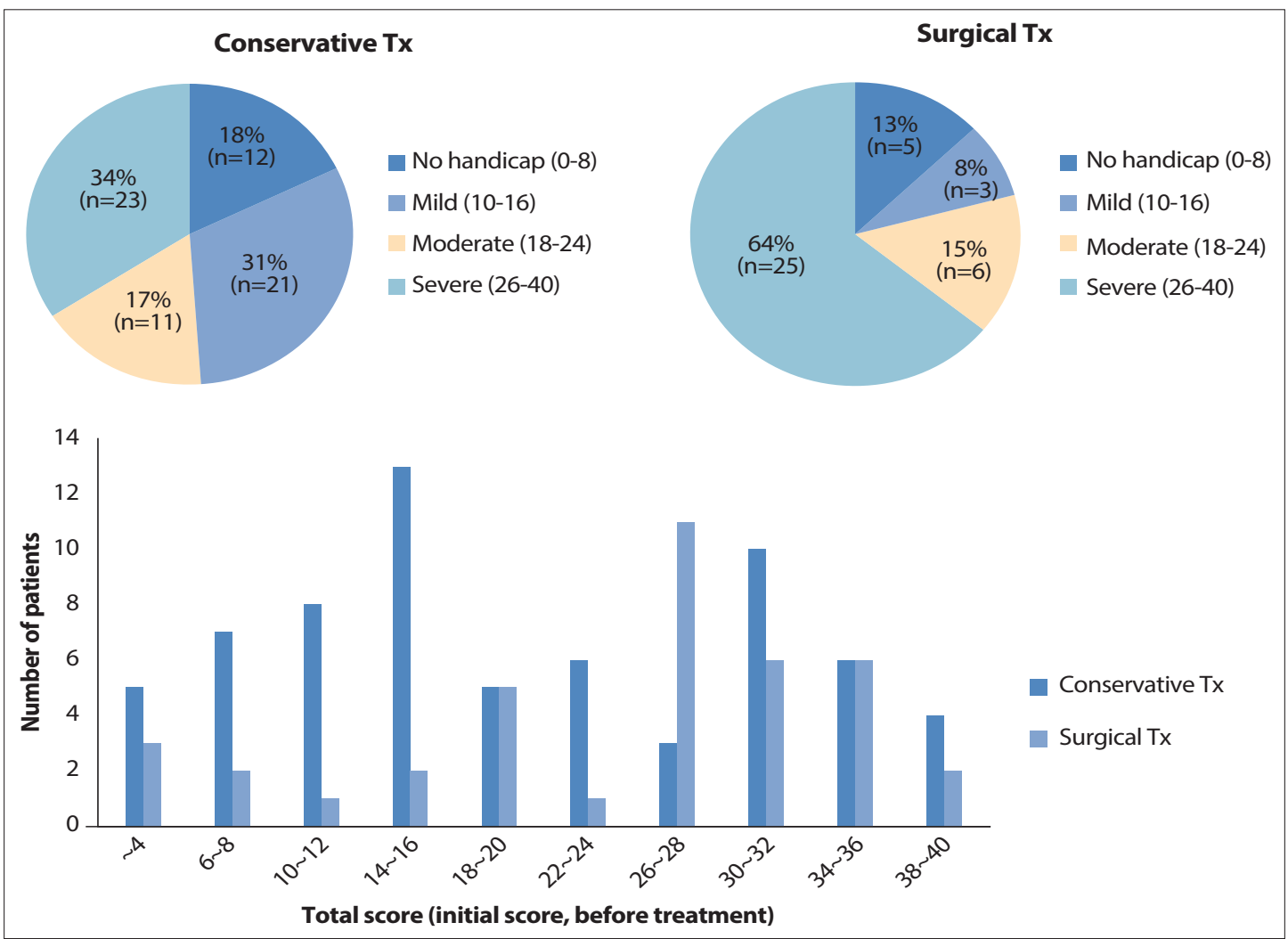

Fig. 1. Severity distribution by K-PHI category, before treatment. According to the categorization of K-PHI scores, the upper pie graphs (A, B) show the severity distribution of the conservative treatment group (A) and surgical treatment group (B). And lower bar graph (C) shows distribution of severity according to total score of K-PHI. Tx: treatment, $\mathrm{K}-\mathrm{PHI}$ : Korean version of PHI. 
K-PHI was $23.6 \pm 10.3$ before the surgery and $14.5 \pm 12.2$ after the surgery. The average difference of K-PHI after the surgical treatment was $9.0 \pm 14.0$ (Fig. 2).

\section{Discussion}

The Eustachian tube is closed most of the time in the resting position and opened with swallow, yawns, voluntary or involuntary efforts, and the supine position. Through these actions, the Eustachian tube protects the middle ear from nasopharyngeal stimulants, drains middle ear secretions, and maintains middle ear gas exchange. ${ }^{2)}$ When there is an abnormally widened or continuously opened Eustachian tube, a PET can be diagnosed.

In Ikeda's study, ${ }^{3)}$ the PHI is verified as an effective evaluation tool for the severity of PET, not for screening or diagnosis. Therefore, an accurate diagnosis must be made first. In this study, PET was diagnosed according to the diagnostic criteria of the Japan Otological Society. ${ }^{4}$ If the patient had one or more subjective symptoms and clear symptoms improving with tubal obstruction procedures or objective PET findings, the patient diagnosed as definite PET. But the patient had only subjective symptoms for PET and no other objective findings or symptom improving with tubal obstruc- tion procedures, the patient diagnosed as possible PET. For accurate diagnosis, when the patients complained of symptoms such as autophony or aural fullness with normal hearing threshold and normal tympanometry, we checked if there was a specific situation that improved their symptoms and conducted an otoscopic exam to visualize the medial and lateral movement of the tympanic membrane coincident with forceful respiration while compressing the contralateral nostril. In this study, both definite and possible PET cases were included.

Even after the accurate diagnosis for PET was made, appropriate treatment for each patient can be different by the patient's main complaint, impacts on life quality, or personal preference. Therefore, for effective symptom control, it is important to evaluate the severity of subjective PET symptoms.

Patients diagnosed with PET have symptoms similar to those of tinnitus and complain of reduced quality of life and symptom-induced stress. Therefore, like tinnitus handicap inventory (THI) for THI suffers, an appropriate scoring system for PET can be made with modification and validation of THI questionnaire. The THI is a reliable and validated questionnaire, ${ }^{5)}$ and it is applied in many countries. ${ }^{6-9)}$ Ikeda et al., made new scoring system, modified from THI-12., ${ }^{3,5)}$ Except for questions 8 and 12 of THI-12, the other ten questions are applica-
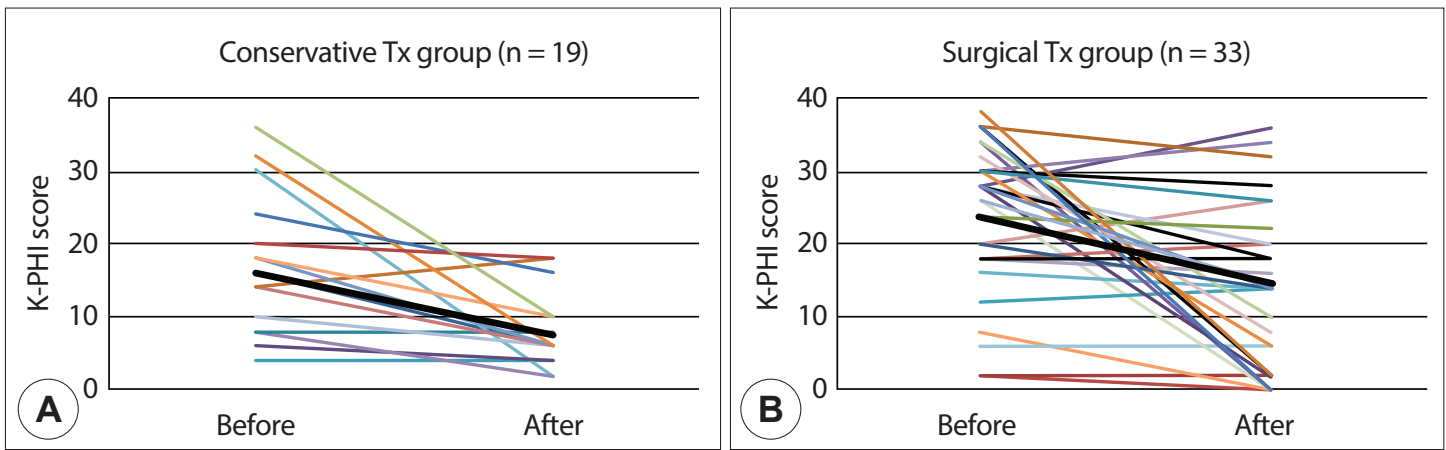

Fig. 2. K-PHI score before and after the treatments. (A) shows the K-PHI score before and after conservative treatment. (B) shows the K-PHI score before and after surgical treatment. The black colored thick line represents the average value of each of the two graphs.

Tx: treatment, K-PHI: Korean version of PHI. 
ble to PET patients, and its effectiveness for evaluating the severity of PET is verified. ${ }^{3)}$ Although there are several questionnaires for Eustachian tube dysfunction, such as ETDQ-7, ${ }^{10)}$ they are not specific for PET, so they cannot reflect the severity of their symptoms and effect on their quality of life.

Cronbach's alpha values of the K-PHI were 0.889 , and Table 2 shows an internal consistency similar to 0.887 of Ikeda et al. ${ }^{3)}$ Based on the 2-tailed significant values less than 0.05 in Table 3, there are significant relationships between each ten items and the total items. Moreover, there were significant relationships between K-PHI and the three VAS symptom scores $(p<0.05)$ (Table 4). Therefore, the results of this study showed that the K-PHI is reliable and valid.

There was a significant difference between the two treatment groups in K-PHI category $(\mathrm{p}<0.05)$ (Fig. 1). And both treatment groups showed remarkable improvement after the treatments in K-PHI score, but there is no significant difference between the two treatment methods (Fig. 2). These results mean that treatment methods tend to be selected according to the severity of the PET patient, and both treatments are effective for PET.

However, this study has a few limitations. First, more than a half of patients included in this study (55 out of 106) had PET in both sides, and the severity of both sides was not always the same. This means that many patients have severe PET on one side and mild PET on the other side. If the more severe side was treated with surgical treatment, the patient was included in the surgical treatment group, regardless of the treatment on the other side. Then, many of them tended to complain of continued or aggravated discomfort after the first surgery on one side because they still had PET on the other side. Therefore, K-PHI score of some patients were elevated even after the treatment in Fig. 2. Second, the treatment method for each patient was not always selected according to their severity, and some- times according to the patients' preferences. Therefore, the conservative treatment group included patients with severe PET who refused surgical management. Third, according to the fundamental purpose of the questionnaire, this study reflected only the severity of subjective symptoms. Fourth, as a limitation of retrospective study, just less than half of patients did follow-up K-PHI after the treatment.

In further studies, PET patients with different severities between both sides should be excluded and objective endoscopic findings should also be analyzed. And through prospective study, follow-up test in most participants should be made. Moreover, efficacy of each treatment methods in the same severity categories should be evaluated.

\section{Acknowledgements}

This work was supported by clinical research grant from Pusan National University Hospital in 2021.

\section{Funding Information}

Not applicable.

\section{Conflicts of Interest}

No potential conflict of interest relevant to this article was reported.

\section{ORCID}

Ji-A Kim, https://orcid.org/0000-0001-9797-5135

Sung-Won Choi, https://orcid.org/0000-0002-7463-7720

Se-Joon Oh, https://orcid.org/0000-0001-8910-0064

Soo-Keun Kong, https://orcid.org/0000-0002-6783-3766

\section{Author Contribution}

Data curation: Choi SW, Oh SJ.

Validation: Kim JA.

Investigation: Choi SW, Oh SJ.

Writing - original draft: Kim JA.

Writing - review \& editing: Kim JA, Choi SW, Oh SJ, Kong SK.

\section{Ethics Approval}

This study was approved by our Institutional Review Board in Pusan National University Hospital, Korea (IRB No. 2102-002099). 


\section{References}

1) Poe DS. Diagnosis and management of the patulous Eustachian tube. Otol Neurotol 2007;28(5):668-77.

2) Sadé J. Eustachian tube function. Acta Otolaryngol 1984;98 Suppl 418:83-4.

3) Ikeda R, Kikuchi T, Oshima H, Miyazaki H, Hidaka H, Kawase T, et al. New scoring system for evaluating patulous Eustachian tube patients. Otol Neurotol 2017;38(5):708-13.

4) Kobayashi T, Morita M, Yoshioka S, Mizuta K, Ohta S, Kikuchi T, et al. Diagnostic criteria for patulous Eustachian tube: a proposal by the Japan Otological Society. Auris Nasus Larynx 2018;45(1):1-5.

5) Bankstahl US, Elkin EP, Gebauer A, Görtelmeyer R. Validation of the THI-12 questionnaire for international use in assessing tinnitus: a multi-centre, prospective, observational study. Int J Audiol 2012;51(9):671-7.

6) Wasano K, Kanzaki S, Sakashita T, Takahashi M, Inoue Y, Saito H, et al. A psychometric validation of the Japanese versions of new questionnaires on tinnitus (THI-12, TRS, TRSw, TSS, and TSSw). Acta Otolaryngol 2013;133(5):4918.

7) Meng Z, Zheng Y, Liu S, Wang K, Kong X, Tao Y, et al. Reliablity and validity of the chinese (mandarin) tinnitus handicap inventory. Clin Exp Otorhinolaryngol 2012;5(1):10-6.

8) Monzani D, Genovese E, Marrara A, Gherpelli C, Pingani L, Forghieri M, et al. Validity of the Italian adaptation of the Tinnitus Handicap Inventory; focus on quality of life and psychological distress in tinnitus-sufferers. Acta Otorhinolaryngol Ital 2008;28(3):126-34.

9) Nahad HA, Rouzbahani M, Jarollahi F, Jalaie S, Pourbakht A, Mokrian H, et al. Translation, validity, and reliability of a persian version of the iowa tinnitus handicap questionnaire. Iran J Otorhinolaryngol 2014;26(75):79-88.

10) Ikeda R, Kikuchi T, Miyazaki H, Hidaka H, Kawase T, Katori Y, et al. The efficacy of the Eustachian Tube Dysfunction Questionnaire (ETDQ-7) for patulous Eustachian tube patient. Acta Otolaryngol 2018;138(1):6-9.

\section{Appendix}

Appendix Table 1A. Korean version - Patulous Eustachian-tube handicap inventory (한국어판 개방성이관 증상설문지, $\mathrm{K}-\mathrm{PH}$ )

\begin{tabular}{|c|c|c|c|c|}
\hline \multirow{2}{*}{ Factor } & \multirow{2}{*}{ 항 목 } & \multicolumn{3}{|c|}{ 점 수 } \\
\hline & & 4점 & 2점 & 0점 \\
\hline $1 \mathrm{~F}$ & 증상 때문에 집중하기가 어렵습니까? & 그렇다 & 가끔 그렇다 & 아니다 \\
\hline $2 \mathrm{~F}$ & 증상의 크기로 인해 다른 사람이 말하는 것을 듣기가 어렵습니까? & 그렇다 & 가끔 그렇다 & 아니다 \\
\hline $3 \mathrm{E}$ & 증상으로 인해 화가 날 때가 있습니까? & 그렇다 & 가끔 그렇다 & 아니다 \\
\hline $4 \mathrm{C}$ & 증상에서 벗어날 수 없다고 생각하십니까? & 그렇다 & 가끔 그렇다 & 아니다 \\
\hline $5 \mathrm{~F}$ & 증상으로 인해 사회적 활동에 방해를 받습니까(예. 외식, 영화 감상)? & 그렇다 & 가끔 그렇다 & 아니다 \\
\hline $6 \mathrm{E}$ & 증상 때문에 좌절감을 느끼는 경우가 있습니까? & 그렇다 & 가끔 그렇다 & 아니다 \\
\hline $7 \mathrm{~F}$ & 증상으로 인해 업무나 가사 일을 하는데 방해를 받습니까? & 그렇다 & 가끔 그렇다 & 아니다 \\
\hline $8 \mathrm{E}$ & 증상이 가족이나 친구 관계에 스트레스를 준다고 느끼십니까? & 그렇다 & 가끔 그렇다 & 아니다 \\
\hline $9 \mathrm{~F}$ & 증상에서 벗어나 다른 일들에 주의를 집중하기가 어렵습니까? & 그렇다 & 가끔 그렇다 & 아니다 \\
\hline $10 \mathrm{E}$ & 증상으로 인해 불안감을 느끼십니까? & 그렇다 & 가끔 그렇다 & 아니다 \\
\hline & TOTAL SCORE: 점 & \multicolumn{3}{|c|}{$\begin{array}{c}0-8: \text { no handicap } \\
\text { 10-16: mild handicap } \\
\text { 18-24: moderate handicap } \\
\text { 26-40: severe handicap }\end{array}$} \\
\hline
\end{tabular}

